\title{
Differenz
}

Revista internacional de estudios heideggerianos y sus derivas contemporáneas

AÑO 6 NÚMERO 5: JULIO DE 2019. e-ISSN: 2386-4877 - DOI: 10.12795/DIFFERENZ.2019.105.05

[pp. 91-118]

Recibido: 10/03/2019

Aceptado: 25/06/2019

\section{El texto que obra: La filosofía como (si) arte}

\section{The text that works: Philosophy as (if) arts}

\author{
Carlos Segovia \\ Universidad Nacional de Educación a Distancia
}

\section{Resumen:}

Este texto lee, desde el punto de vista de Derrida, la controversia entre Heidegger y Schapiro acerca de ciertas botas pintadas por Van Gogh. Se discute aquí la maniobra del especialista como apropiación indebida cuando Schapiro dice de forma implícita y perversa: yo soy el dueño de las botas de Van Gogh. Se discute el concepto de verdad que Heidegger propone para el arte. Finalmente, se propone la figura del filósofo como escritor y, por tanto, como artista.

Palabras clave: Heidegger; Derrida; Van Gogh; pintura; verdad.

\section{Abstract:}

This text reads, from Derrida's point of view, the controversy between Heidegger and Schapiro about certain boots painted by van Gogh. The specialist's maneuver is discussed 
here as misappropriation when Schapiro says implicitly and perversely: I am the owner of Van Gogh's boots. The concept of truth that Heidegger proposes for art is discussed. Finally, the figure of the philosopher as a writer is proposed and, therefore, as an artist.

Keywords: Heidegger; Derrida; Van Gogh; painting; true.

Escribir, si es posible (...) finalmente, ni siquiera uno mismo. Jacques Derrida, Párergon

\section{El discurso del especialista: apropiación, marco y atribución ${ }^{1}$.}

Manejaré aquí dos textos principales: El origen de la obra de arte ${ }^{2}$ y La verdad en pintura ${ }^{3}$, además de las ramificaciones que de este tronco textual puedan surgir. La cuestión central arranca de un par de botas pintadas -o de dos botas, sin que resulte tan evidente que se trate de un par-, que no están hechas para caminar o para tocar el suelo sino para vestir paredes, que no se han creado para que sean calzadas sino para ser vistas, que no se han fabricado para los pies sino que se han creado para los ojos. Nuestra cuestión toma cuerpo a partir de esa corrección o ajuste de cuentas que Schapiro le hace a Heidegger acerca del título de propiedad de esas botas que no están en ninguna parte, del debate acerca de si se trata de unas botas de campesino o de campesina o, por el contrario, de una botas que se calzan para patear no los campos sino la ciudad. Lo que en cierta medida mueve mi texto es la cuestión de la verdad, de esa verdad que no poseemos, que quizá no queremos ver ni en pintura. Por tanto, comienzo o continuo.

Lo primero que quiero recoger del texto de Derrida leyendo a Heidegger es un comentario como al margen que, como todo lo marginal, merece atención más allá de su anécdota.

1 Este texto se integra en el marco del Proyecto de investigación, Estudio sistemático de las lecturas heideggerianas de Jacques Derrida. Confluencias y divergencias (FFI2016-77574-P) del Ministerio de Economía, Industria y Competitividad (Dirección General de Investigación y Gestión del Plan Nacional de I+D), cofinanciado por la Agencia Estatal de Investigación (AEI) y el Fondo Europeo de Desarrollo Regional (FEDER, UE).

2 HEIDEGGER, M. El origen de la obra de arte. Oficina de Arte y Ediciones, 2016. A partir de ahora $E O A$

3 DERRIDA, J. La verdad en pintura. Buenos Aires: Paidós, 2009. A partir de ahora LVP. 
Siempre tengo la impresión que comentando a Heidegger (...) le hacemos decir una cosa completamente diferente, cambiamos todos los acentos, ya no reconocemos su lengua. El comentario se torna obsceno ${ }^{4}$.

Leyendo a Derrida leyendo a Heidegger. Este gerundio doble indica cierto vacío central, cierta pintura en blanco de la que solo hablaremos en relación a su marco, cuya moldura virtual no contiene ni un texto ni una pipa, ni traducción ni representación de algo que estaría fuera de marco o fuera de obra. No saldremos, por tanto, del marco. Ni un paso más allá.

Leyendo a Derrida leyendo a Heidegger. Lectura sin explicación, sin traducción, sin pautas normativas, porque ni yo ni nadie puede explicar un texto de Derrida o de Heidegger. Ni yo ni nadie; ni siquiera los propios autores de un texto pueden explicarlo sin crear ya otro texto. No hay hermenéutica sino archilectura, no hay traducción o explicación o puesta en claro de texto alguno -ni tampoco llevar el texto hacia algún claro que ilumine su sentido-, sino que lo que hay es un gesto doble de lectoescritura por el que leer implica ya escribir, por el que cualquier intento de explicación ha de asumir y comprometerse con el propio texto que pone a obrar. No hay explicación neutra, que no dependa de nuevo de un texto.

Aquí, en este terreno que ahora se acota, todo especialista es un impostor. Dentro de este marco, considero el afán del especialista como una operación fraudulenta a través de la cual intenta erigirse como propietario de aquello sobre lo que está supuestamente especializado. Cuando Schapiro "discute" con Heidegger -en verdad discute con "su" texto, con el texto de Heidegger que él lee, con cierto espectro textual que él toma como lo que defiende Heidegger, a fin de cuentas, con el texto que él, Schapiro, elabora mientras lee a Heidegger-, cuando insiste en restituir esas botas a su legítimo propietario, como sin en verdad se tratase de botas y no de la pintura -que no representación o imagen- de unas botas -como si de verdad fuese importante si esas botas son de él o de ella, de la mujer o del hombre, del campo o la ciudad-, cuando Schapiro insiste una y otra vez en devolver ese par de botas a su legítimo dueño, lo que en el fondo subyace es aquello implícito siempre en el discurso del especialista, lo que en verdad está diciendo Schapiro es lo siguiente: las botas son mías, el cuadro de Van Gogh y el mismo Van Gogh son míos, mi área de especialización y pertenencia, el contenido de mi marco, mi propiedad. Yo soy el gallo del corral.

Una primera precaución aquí debería tener en cuenta que el texto de Derrida no es nuestro, que el texto de Heidegger no es nuestro, apenas quizá ya de ellos; que no hay

4 Ib. p. 317. 
"especialistas" sobre Derrida o Heidegger si con ello entendemos el más mínimo derecho de propiedad o incluso de pernada sobre uno u otro.

En el discurso del especialista, quizá cercano a lo que Lacan llama "lenguaje universitario", se produce con demasiada frecuencia un desplazamiento inasumible: la incapacidad ante el propio texto se transforma en vigilancia ante el texto que el especialista se apropia; la ausencia de compromiso ante el propio texto que se pone a obrar en cuanto se activa la lectura provoca que, en lugar del compromiso con la propia letra, encontremos una supuesta explicación, una traducción intralingüística que, en una puesta en escena notarial, insípida tantas veces, toma un texto ajeno que termina haciendo pasar por propio. Tengamos en cuenta, para no caer en lo que a partir de ahora llamaré la "maniobra Schapiro", que la especialización no implica nunca un título de propiedad, y que, por otro lado, no hay jamás especialización absoluta o total sobre ámbito alguno. Y por último: el discurso del especialista no es la coartada para elaborar un discurso no comprometido con el propio texto que pone a obrar, o dicho de otra forma: el discurso del especialista, del académico, no puede limitarse tampoco a una escritura ingenua, que se crea explicativa, al margen del estilo, que se piense vehículo de un pensamiento independiente de su propio escribirse y que se limita, nada más y nada menos, que a iluminar o aclarar el texto que se apropia. Al igual que ocurre en esa película de serie $B$ donde cientos de vainas alienígenas comienzan a caer en la Tierra, y que durante la noche aprovechan el sueño de los humanos para suplantarlos, la copia vendría siempre a ser más pálida y gris que el original; sin resto de vida orgánica alguna ${ }^{5}$. Precisamente porque no hay nunca "un" original, un modelo primigenio, justo porque todo original es ya copia, el texto que abre toda lectura no puede partir de un presupuesto equivocado, el de creerse apéndice o suplemento de un supuesto original, mero afluente de la fuente primigenia que vendría a ser el texto que comenta o explica.

Leyendo a Derrida leyendo a Heidegger. Agarrado al marco, de una mano, hago mía, entonces, la advertencia o la duda de Derrida cuando leyendo a Heidegger se pregunta cómo no hacerle decir otra cosa. Pero cómo no hacerle decir otra cosa también a Derrida, o cómo no hacerle decir otra cosa a nuestro propio texto, cómo no hacerle decir otra cosa al mismo decir, al lenguaje, a la escritura. Porque esta es la única garantía con la que contamos: que hay que arriesgarse a no decir nada; o arriesgarse a que, finalmente, se termine diciendo siempre otra cosa.

Leyendo a Derrida leyendo a Heidegger. Aplicarse a la lectura con una lupa que no sea la lupa policial o la del agente del orden, que no busque, como en el caso de Schapiro

5 SIEGEL, D. La invasión de los ladrones de cuerpos. EEUU, Allied Artists, 1956. 
discutiéndole a Heidegger el propietario de esas botas del cuadro de Van Gogh, una transferencia de propiedad por la que, siguiendo una ley fuera de toda justicia, intenta él mismo proponerse, de forma tácita pero siguiendo una táctica propia de todo especialista, como dueño último o verdadero propietario de la pintura de Van Gogh y por extensión de su firma, como si solo lo afirmado por Schapiro, el especialista, rubricase la firma de Van Gogh, el artista.

Advertidos de esto, no daremos aquí un paso que nos expulse hacia esa zona o esa tierra.

Para comenzar, o para continuar, quisiera marcar la proposición que aquí dirigirá este texto: el filósofo es un artista. Creo que es suficientemente incómoda como para poder continuar a partir de ella. Hasta la fecha solo me había animado a afirmar lo siguiente: el filósofo es un escritor ${ }^{6}$. Por supuesto, esta propuesta bebe de Deleuze y Guattari, pero tomando escritura como archiescritura, es decir, no confundiéndola con notación o grafía, sino entendiéndola como posibilidad de lenguaje. Sobre todo esto ya me he extendido y quizá excedido suficiente, y cualquier detención ahora me impide ese no paso que aquí persigo.

El filósofo es un escritor, el filósofo es un artista, como si algo así se dejase decir, como si proposiciones como esas se pudiesen formular y seguir viaje. Se entendería, entonces, que hay algo así como "el filósofo", y que hay algo así como "el escritor" o incluso "el arte". Al igual que cuando se defiende que el compromiso del filósofo es con la verdad se entiende que hay algo así como "la verdad", se acepta, por tanto, la existencia de una verdad previa con la que el filósofo, entendido de cierta manera, se comprometería. Constantemente, este tipo de afirmaciones vacías desplazan el centro de aquello que pretenden traer o nombrar, constantemente no se dice qué es un filósofo, qué es la escritura o qué es el arte o qué es la verdad. En todo momento un fantasma recorre el texto. Pero ¿hay que responder aún a ese "qué"?, ¿`se pueden seguir formulando, a estas alturas del juego, preguntas con esa estructura?, ¿que demanden definiciones rígidas, dominadas por el totalitarismo semántico y la barbarie del enciclopedismo?

Arranquemos, por tanto -y aunque en verdad se trate de no arrancar-, con esta hipótesis: el filósofo es un artista; sin que esta proposición deba entenderse como respuesta a alguna pregunta implícita. Nos encontraríamos, en todo caso, ante una respuesta que pregunta, ante una reacción sin causa, ante una procedencia sin antecedente.

6 SEGOVIA, C: "El sujeto narrado: poner a pensar la escritura”. Revista Electrónica de Investigación en Filosofía y Antropología. Decanato de Filosofía. UNED, 2017. 
Hipótesis que no viene de la nada, sino que enlaza con la que afirma que el filósofo es un escritor, con la propuesta que defiende que el compromiso del filósofo no es con la verdad sino con la escritura, con una escritura no ingenua, esto es: una escritura que no es mero vehículo de un pensamiento que podría no estar escrito, que no se confunde con un pensamiento que vive y respira más allá de su puesta de largo en el lenguaje y cuya verdad incorruptible existe al margen de su encarnación en la materialidad de una escritura ideal. A fin de cuentas, el filósofo al que aquí llamo escritor no deja de ser consciente de que todo "su" pensamiento pasa por "poner a pensar la escritura".

Siguiendo esta línea afirmo que el filósofo es un artista, sin que, por supuesto, deba entenderse por esta palabra: "artista", algo evidente, habitual, masticado, común o banal. Siguiendo esta línea, afirmo que el filósofo es un artista porque su trabajo es "poner a obrar el texto"; no poner a obrar la verdad en el texto, sino "poner en obra el texto", que será, a fin de cuentas, su única verdad.

Poner a obrar el texto, poner en obra la letra, me detendré en esto más adelante. Muy pronto.

El discurso del especialista precisa de su aparato policial: notas al pie, citas, fuentes bibliográficas, epígrafes, palabras clave, resúmenes, una introducción que declare qué o a quién se va a investigar y unas conclusiones que a modo de informe cierren el expediente. Y no solo esto, sino una "seriedad" en su lenguaje expositivo, una concisión estructural que raye en ocasiones en lo insípido, el acta notarial, la resolución del juez. El especialista no se dedica al arte sino a la verdad. El discurso del especialista está acotado no solo a nivel formal, sino a nivel de contenido, a nivel de estructura y disposición de sus partes; un hilo claro, una serie de proposiciones o hipótesis encadenadas entre sí por la causalidad, etc. Valga a modo ejemplo la estructura del $I M R a D^{7}$ como uno de esos contenedores para el discurso del especialista que, a fin de cuentas, se diseñan con el único fin de no escribir y no leer. Este es el marco que el especialista nunca sobrepasa. Es como esas figuras cuyas partes en blanco están numeradas para que el niño las coloree sin salirse fuera de las líneas marcadas.

El discurso del especialista, lo que aquí estoy nombrando así, no se limita solo a la academia o a un ámbito especializado, no se limita solo a ciertas marcas visibles en el formato del texto (notas, citas, bibliografía) sino que llevando esto un punto más allá, la maniobra del especialista se cuela también en el texto, llamémosle, "artístico", gracias

7 Introduction, Methodology, Results and Discussion. Se trata de una estructura cuya mayor virtud es una estructuración de los contenidos que permiten realizar una lectura rápida, un escaneo sin necesidad de lectura profunda, esto es, cuya mayor virtud consiste en no leer. 
al uso de estructuras narrativas preconcebidas, precocinadas, calculadas para provocar la reacción del receptor, etc. La especialización como oficio se cuela en el ámbito del supuesto arte ${ }^{8}$.

Frente al discurso del especialista, que pone en juego una escritura ingenua, que se piensa vehículo de comunicación o conocimiento, que se cree traducción de un pensamiento que no depende del lenguaje que lo materializa y que, por tanto, podría estar escrito o no, frente a la maniobra del especialista, que cree que es posible contar la misma historia cientos de veces, la filosofía, la literatura, entendidas como arte, (entendidas de la única forma posible) ponen a obrar un texto. El filósofo, el escritor, se compromete con su trazo, con la escritura que pone a pensar. Este compromiso, y no su contenido, es la única verdad.

No deja de funcionar aquí la evidencia del par, como ocurre con esas botas de campesina o ciudadano que Schapiro se apropia mientras les busca propietario, porque esto, que son un par, que no se trata de una bota y otra, dispares, de diferentes números y pies, esto es algo que tanto Heidegger como Schapiro toman como evidente. El par entre el original y la copia, entre texto y metatexto, entre lenguaje y escritura, entre acción y teoría, este par gastado y roído por las puntas y con la suelas desclavadas de la horma pide, también, abandonar el camino, dejarle el paso a otras formas de vérnoslas con las cosas que no pase por el filtro de la vieja rejilla.

Schapiro, el especialista, se apropia de la obra, de la pintura de esas botas, de la firma de Van Gogh, que son para aquel un fetiche mayor de lo que jamás sería la oreja rebanada de este.

Ejemplo de Schapiro como especialista, como si la pintura y Van Gogh y sus cuadros fuesen algo suyo; en verdad, como si la atribución no fuese a quién le pertenecen esos zapatos, esa pintura, sino que el subtexto afirmaría: todo eso es mío, del especialista, del que genera cierta plusvalía de sentido, como si el especialista fuese el amo que viene a apropiarse de la mano de obra, del trabajo que no hace, que no suda, que no paga con su sangre. Y quizá, hay todavía que insistir en un decir, una crítica, una filosofía que no se apropie, que no tome en usufructo lo que no le pertenece, sino que genere su propio texto, su propio acontecimiento, no la verdad sino el compromiso con la letra, con su

\footnotetext{
8 La industria del cine, por ejemplo, ha calculado incluso en qué minuto de la película el guion ha de plantear el desencadenante de la historia, en qué minuto un punto de giro u otro para que el espectador se enganche, no se aburra, mantenga su cada vez menos resistente atención. Así, lo único que hay que hacer es cambiar los contenidos de esa cadena de montaje que en relación a su engranaje no cambia.
} 
escritura. Para ello, hay que escribir, no hacer de escriba o de amanuense, sino escribir, poner a pensar la escritura. Para ello hace falta, quizá, menos oficio y más arte ${ }^{9}$.

Heidegger no se presenta como un especialista en arte, Derrida no se presenta como un especialista en Heidegger, nada queda más lejos de un escritor que la especialización, que el academicismo, que cierta forma de entenderse profesional.

Lo que defenderé a continuación es que el filósofo es un escritor, y que el escritor es un artista, sin que estas palabras: "escritor", "artista" deban entenderse como algo evidente, en un sentido habitual, común. Lo sabemos, que se trata de dos palabras gastadas, vaciadas de todo contenido (si incluso se llega al despropósito de llamar arte a la tortura de animales que practica la tauromaquia), palabras que hay, por tanto, que reformular, que volver a escribir.

En este primer tramo de texto han surgido al menos tres cuestiones que tienen que ver con el discurso del especialista y que trataré a continuación para oponer a este tipo de maniobras el texto que obra. Estas tres cuestiones son la de la apropiación, la del marco y la de la atribución. Apropiación del objeto de estudio, ya sea el cuadro de Van Gogh o el mismo Van Gogh; defensa del marco que limita el terreno donde el especialista gobierna y se convierte en señor de sus tierras; atribución de un contenido falseado o que simplemente empalidece ante aquello que toma, como crear una vaina alienígena a partir de un cuerpo que estaba vivo.

\section{El contrato, el par: evidencia y representación}

Derrida insiste en cuestionar el par, que se asuma, sin más, que se trate de un par de botas y no de una bota y otra, o de dos botas que no formarían ningún par; cuestionarse por qué motivo Heidegger y Schapiro aceptan la evidencia de un par ${ }^{10}$. ¿Se trata también de una pregunta algo boba, como ocurre con esa obsesión de Schapiro por encontrarle al "par" de botas su legítimo propietario? ¿Utiliza también Derrida aquí la lupa policial, esa lupa que, a fin de cuentas, busca huellas que nada tienen que ver con nuestro caso, que quedan fuera de la escena del crimen que aquí nos interesa? Veamos ${ }^{11}$.

9 "La apariencia de que la creación de obras es también una actividad artesanal, cosa que no es jamás". EOA. p. 113.

10 "¿Qué es un par en este caso, y de dónde sacan ambos que Van Gogh pintó un par? Nada lo prueba". LVP. p. 278.

11 Sobre la cuestión de esa lupa policial, esa lupa que trata de explicar el texto, que intenta siempre cerrar un texto como si se tratase de un expediente policial a archivar, Derrida deja escrito: "Todo se convierte en uno de esos ejercicios de lectura con lupa que pretenden dictar la ley tranquilamente, 
Schapiro quiere saber a quién le pertenecen esas botas, cuál fue su utilidad, si se trata de unas botas de una campesina o de un urbanita, si esas botas se han creado para los campos o para el pavimento, llega incluso a argumentar que en la época en la que Van Gogh pinta esas botas sobre lienzo, éste no se encontraba viviendo o malviviendo en el campo sino en la ciudad; como si se diese por hecho que hay un modelo, un original que el artista imita o copia o reproduce, como si se diese por hecho que Van Gogh no podría recordar o imaginar esas botas que pinta, o que, por proponer aquí cualquier otra hipótesis estéril, simplemente es que ha viajado con esas botas desde el campo a la ciudad, o que podría tratarse de un cuadro que esboza en el campo y finaliza en la ciudad. A fin de cuentas, todas estas cuestiones fundamentales para el especialista, aquí nos importan menos que nada ${ }^{12}$. Lo que sí quiero poner de manifiesto, es que si Derrida insiste en la cuestión del par es porque esta asunción de la evidencia del par corre paralela a la asunción del contrato por la que el especialista se hace posible como profesional de cierto saber. Esta cuestión del par es la cuestión, por tanto, del contrato, de cierto contrato tácito, implícito, que ninguna de las partes firma pero no por ello deja de asumir y que va más allá de la maniobra del especialista a la que me estoy refiriendo aquí. Y este contrato está obligado a asumir cierta evidencia donde la duda se detiene o no se plantea, cierto suelo donde tomar pie, cierto primer principio del que se parte; también -quizá, sobre todo- cierta utilidad. Se firma un contrato para algo. Cuestionarse que no se trata de un par pone a su vez en cuestión el contrato, la utilidad, nos reenvía al diabolismo de la asimetría, al fetichismo de las cosas fuera de uso, desterradas fuera de marco, a la aniquilación de los códigos que mantienen en pie la ficción de cierta realidad que asumimos como evidente, ahí, a mano.

El par, digámoslo ya de una vez, es la vieja rejilla, la bivalencia metafísica, es decir, todo eso que ya sabemos: la distinción entre la génesis y el devenir, entre el original y la copia, entre el lógos y el lenguaje, entre el habla y la escritura. La verdad, en el interior del par, bajo la letra de este contrato, se da en el sentido de adecuación, en el sentido de que una de la partes se adecue y refleje la otra. La copia será verdadera en la medida en que reproduzca el original, el lenguaje lo será en la medida en que se ajuste al pensamiento que

controlarlo todo, de manera policial, en efecto". Ib. p. 25. Lo que estoy intentando aquí es no confundir, que no se confunda, esta lupa policial con la lupa "deconstruccionista" del propio Derrida, ya que la de este no se pone en acción para cerrar o determinar la Ley o la Verdad de un texto.

12 "El recurso dogmático a la evidencia manifiesta suena aquí como un decreto. (...) La prueba es entonces curiosamente 'externa': la fecha presunta de los cuadros. Presunta porque solo uno de los tres indica 'Vincent 87', si esto se considera una prueba. En esta fecha presunta, Van Gogh estaba en París, ilejos de los campesinos! iEntonces no pudo haber pintado zapatos de campesino! Esta conclusión triunfal bastaría para sorprender". Ib. pp. 375-376. 
pretende traducir. Lo que ocurre es que este contrato es, desde hace mucho, hojarasca, una colección de claúsulas roídas por la polilla, papel mojado, porque la cuestión de la representación, de la traducción, de la copia, del reflejo no se sostiene, ni en el arte ni en ninguna parte. No puedo entrar ahora en todo lo que implica la crisis de la representación, en todo lo que implicaría a nivel de lenguaje, al nivel de arte, a nivel de conocimiento o a nivel político, en lo que supone de lastre este contrato que insiste aún, en los tiempos que corren y que no esperan por nosotros, en estos tiempos a los que, por otra parte, les da lo mismo que nos sigamos manejando con conceptos que han dejado de estar a la altura de su tempo, lo que supone este contrato de bestiada, de un saber que no quiere saber.

Insisto en la asunción acrítica y evidente del par como la asunción acrítica y evidente del contrato que hace posible que el experto cumpla con su función, y este contrato, la evidencia de lo que este contrato asume, hay que llevarlo un poco más lejos -solo un poco- de esa proclama en la que nadie puede ya creer pero que sirve aún como contra argumento para atacar las formas que ha venido tomando el arte contemporáneo, la forma en la que se sigue entendiendo el trabajo del especialista. El gran equívoco en el arte es seguir aplicando el modelo de la "mímesis", es seguir creyendo que la obra imita la realidad, que copia o reproduce algún modelo del mundo real. No solo se trata de que esto no es ya así, sino que nunca ha sido así, ni en las pinturas de corte ni en las naturalezas muertas, ni en los retratos ni en las escenas de caza, nunca, la obra de arte se ha dedicado ha reproducir algo real, algo que estaba antes que ella, ahí en el mundo, y que se limitaría a copiar. Tampoco hay texto alguno que explique los textos de Derrida o de Heidegger, mucho menos que resuma o sintetice el "Libro-Derrida" o el "Libro-Heidegger", si por esto entendemos cierta clausura de un sistema como totalidad.

Moviéndonos entonces del campo del arte al distrito de los textos, en el plano del especialista que analiza o explica un texto de Heidegger o de Derrida, este par que evidencia el contrato por el cual se da un original y una copia, un texto fuente y un texto crítico que lo comenta, que realiza sobre él un trabajo hermenéutico, este contrato oculta también esa trampa de la vieja rejilla que se activa en cuanto se toma este par como evidente, como algo previo fuera de toda discusión. Como ya se sabe, una cantidad importante de textos de Derrida surgen a partir de sus lecturas, a partir de otros textos, a partir de un texto de Heidegger, de Husserl, de Levinas, de Foucault, etc., pero lo que Derrida no hace nunca, en ningún caso, es tomar la pose del especialista, lo que no hace nunca es elaborar un texto académico, pedagógico, explicativo, ni siquiera hermenéutico si por esto se tiene en mente aquella máxima que declaraba como objetivo entender el texto mejor que su propio autor. Lo que no hace Derrida es evitar el acontecimiento de su propio texto, o mejor, "en" su propio texto; que el texto que él escribe acontezca, o que 
algo acontezca en él. Lo que hace Derrida, lo que hace un escritor, lo que hace un artista, es poner a obrar el texto, es comprometerse no con la verdad del especialista, sino con el compromiso de "poner a pensar la escritura".

Hasta aquí he intentado sugerir la distancia que media entre escribir en un sentido tradicional, académico, en ese sentido en lo que importa es cierta explicación o contenido al margen del estilo o del compromiso con el propio texto -como si este se limitase a traducir un pensamiento previo, a inscribir en la grafía ciertas conclusiones tras una lectura previa- y escribir en el sentido de "poner a pensar la escritura", en el sentido de una escritura que pone a obrar un texto. Hasta aquí he intentado marcar la distancia, a fin de cuentas, entre escribir y no escribir.

Lo que pretendo a continuación es aclarar en lo posible en qué consiste este gesto que denomino "poner a obrar el texto", y en qué sentido defiendo que el filósofo es un artista. $\mathrm{O}$ que es un escritor $\mathrm{y}$, por tanto, es un artista.

\section{Pero ¿qué es el arte?}

Este modelo de pregunta: ¿qué es?, implica ya la afirmación de que "eso" por lo que se pregunta; se sobreentiende que ese "algo", la "cosa" (aquí el arte), tiene una existencia o realidad o definición más o menos amplia, o si no, al menos un perímetro o un "algo" que podemos reconocerle como propio frente a cualquier otra cosa o habilidad o acción. Además de algo a lo que se le llama "arte" (sin más, a secas, en toda su pureza o universalidad), tenemos también un arte de la cocina, o un arte de la fuga, o incluso, como he dicho ya, un arte de la tauromaquia o un arte de la tortura, esto es, un "arte" no como sustantivo o nombre propio sino más bien como acompañante o adjetivo que "eleva" la habilidad u oficio a algo más que a la mera artesanía, a algo más que la simple utilidad.

Pero volvamos a la estructura de la pregunta. "Qué es" ya responde: "eso es". El "qué es" garantiza "eso" por lo que pregunta. Pero qué arte, se podría preguntar sin que esta formulación asegure aquello por lo que pregunta. Incluso en tono despectivo, como diciendo: pero de qué me habla. Y aun así, el arte y no las artes, ni este arte o aquel; aun así la unidad, la reunión y unificación acerca de aquello que el arte sea o no sea.

Para que la pregunta afirme precisa la cópula, engendrar ya al sujeto por el cual pregunta. Esta cópula denuncia una forma de ver. Esta forma habitual de ver nos llevaría a buscar una serie de características en la obra, unos rasgos que la harían tal. Para Heidegger, esta forma de ver ya no resulta adecuada. Hay una sospecha en él ante 
las comodidades heredadas de la estética y la filosofía del arte, ante ciertos clichés que remiten a la distinción entre forma y materia.

Quiero aquí marcar un paralelismo entre la obra y el texto; ese texto que pasa siempre por su forma lingüística y, por tanto, por la escritura -sea esta inscripción o grafía o no tome cuerpo de letra alguno. Heidegger realiza una comparación entre la cópula del sujeto y el predicado en la oración y la estructura de la cosa como reunión de la substancia con los accidentes ${ }^{13}$. ¿Se trata de entender que el lenguaje refleja la cosa?, o ¿se trata de que la representación de la cosa obedece a la estructura del lenguaje? Pero ¿hay que seguir manteniendo en pie esta cuestión de la representación y el reflejo?, ¿respetar una jerarquía por la que una de las partes en juego sería la primera?, ¿darle crédito a una causalidad por la que la cosa sería el reflejo del lenguaje o este representaría la cosa?

Entonces -preguntábamos-: ¿qué es el arte?

Y como contestar: no es.

Habría que insistir: no hay arte, no hay tal cosa, en ninguna parte hay eso por lo que se pregunta "qué es", porque no se puede contestar en serio a una pregunta como esta, que adopta la estructura del "qué es" de forma acrítica, ingenua, afirmando conocer ya lo suficiente aquello por lo que pregunta como para asegurar que "eso" es algo, que es "él" y no "las". Esta pregunta asegura y admite ya una unidad previa a su interrogación.

A “¿qué es el arte?" solo cabe contestar: pero ¿lo hay?, ¿hay algo como eso en alguna parte?, ¿'se puede tocar, oler, estrujar, palpar, observar, comprar, vender, regalar?

¿Qué es ese "es"? ¿Qué es ser? Esta pregunta debería ir ya por delante de la función gramática, antes de poner el verbo a copular con un sujeto que asegura sin asegurarse, antes de que la simple cópula garantice de inmediato un ser, un "algo" del que pretendemos su "cómo".

Hay cierta circularidad entre la obra y el artista. "Según la representación habitual, la obra surge a partir de la actividad del artista y por medio de ella"14, a lo que Heidegger responde muy pronto:

El artista es el origen de la obra. La obra es el origen del artista. Ninguno puede ser sin el otro. Pero ninguno de los dos sostiene tampoco al otro

13 "En el fondo, ni la estructura de la oración da la medida para diseñar la estructura de la cosa ni esta se refleja simplemente en aquella. Ambas, la estructura de la oración y la de la cosa, tienen su origen en una fuente común más originaria". EOA. p. 33.

14 lb. p. 19. 
por separado. El artista y la obra son, cada uno en sí mismo y también recíprocamente, por medio de un tercero que en definitiva acaba siendo lo primero de todo, puesto que es justamente aquello de donde el artista y la obra de arte reciben sus nombres: el arte $^{15}$.

Aquí y ahora, está claro, no podemos aceptar idealidades abstractas así como así, como si la esencia de eso a lo que se le llama arte, eso que hace posible la existencia de artistas que crean obras de arte, residiese en un mundo aparte del mundo. Lo que propongo es fijar la atención sobre ese tercero entendiéndolo como "entre", como differencia, como "espacio salvaje", como posibilidad de materialización de la idealidad, como la posibilidad de un espacio donde lo ideal y lo material vienen a ser diferentes caras de un mismo rostro -es decir, quizá no entendiéndolo de esta manera o de la otra, quizá no entendiéndolo en absoluto.

Al igual que obra y artista no se sostienen en sí mismos ni sostienen al otro por separado, al igual que solo en esta imbricación hay obra y hay artista, tampoco está lo ideal por un lado y lo material por otro. En el caso que nos ocupa, tampoco hay algo así como la esencia del arte al margen de toda obra y de toda actividad del artista, esa esencia que a través de una mediación casi espiritista se transformaría en obra de ese arte que, como toda idealidad entendida en sentido puro, no se encuentra en ninguna parte. Lo que hay es siempre ese espacio vacío, esa nada productiva, ese campo de batalla donde la obra (el texto) se pone a obrar.

Este poner a obrar es propio también del trabajo textual, de la escritura; este poner a obrar tiene menos que ver con la emergencia de cosas, de objetos de arte, que con la asunción de ese tercero ilocalizable que a pesar de todo se encuentra en todas partes; este poner a obrar tiene que ver con la crisis de dos modelos que no dejan de ser uno: la representación, la traducción. No hay obra creada que reproduzca un modelo ideal, no hay traducción de un pensamiento que podría no decirse en el lenguaje, no hay narración que no se escriba.

La circularidad es indiscernible si no se acepta, como Derrida lo hace ya desde sus primeros textos, que el origen es una complicación en origen, que todo primer principio es ya segundo, que todo significado adopta también posición de significante, que todo original es ya una copia.

Para poder dar un paso más, leyendo a Derrida leyendo a Heidegger (siempre sin "explicarlos", sin atribuirles a ellos lo que aquí se escribe), para seguir camino con esas

$15 \mathrm{lb}$. 
botas pintadas que no están hechas al camino ni fabricadas para calzárselas, para seguir viaje hay que dejar a un lado la verdad como adecuación y entender la verdad en el sentido de desvelamiento.

Más que preguntarse qué verdad muestra la obra, preguntaría, con Heidegger: ¿Qué obra dentro de la obra? ${ }^{16}$ Desocultamiento de lo ente, aletheia, decimos "verdad" sin pensar demasiado. "Cuando ocurre que en la obra se abre lo ente en aquello que es y cómo es, es que está obrando en ella la verdad. En la obra de arte se ha puesto a la obra la verdad de lo ente" ${ }^{17}$.

Pero ojo con esto, ¿supone de nuevo caer en la "mímesis"?, ¿el arte como copia de la realidad?, ¿ ¿representando la verdad del ser? Porque aquí tendríamos de nuevo la verdad como adecuación. ¿Caer una vez y otra en la idea de verdad como reproducción de la esencia general de las cosas? El propio Heidegger reconoce que esto es inverosímili1 ${ }^{18}$.

No hay reproducción, no hay reflejo, no hay traducción, no hay adecuación.

Pero ¿qué verdad ocurre en la obra? O: ¿qué verdad concurre ahí?

¿Es la verdad algo intemporal y supratemporal?, ¿no deja de remitir esta idea de verdad a Dios como reacción ante la propia mortalidad?, ¿no esta verdad, más que un hecho o una aspiración, un síntoma?

La pregunta, por tanto: ¿qué obra dentro de la obra?

No se puede afirmar que lo que obra dentro de la obra sea el artista; su pensamiento, su intención, cierta verdad que deposita en esta. Porque "el artista queda reducido a algo indiferente frente a la obra, casi un simple puente hacia el surgimiento de la obra que luego se anula a sí mismo en la creación"19.

Hay que tener cuidado con este tipo de afirmaciones, porque se podría entender que el artista es un medio del arte para llegar a la obra, un medio de la idealidad para materializarse, un medio de la fábrica de absoluto para producir sus objetos, como si el artista fuese un medio que, una vez conseguido el fin, resulta prescindible. Hay que tener cuidado con este tipo de sentencias porque algo similar es justo lo que ha sentenciado a

16 Ib. p. 57.

$17 \mathrm{lb}$.

18 "Pero ¿acaso opinamos que el mencionado cuadro de Van Gogh copia un par de botas campesinas y que es una obra porque ha conseguido hacerlo? ¿Acaso pensamos que la tela es copia de algo real que él ha sabido convertir en un producto de la producción artística? Nada de esto. (...) en la obra no se trata de la reproducción". Ib. pp. 57 y 59.

19 lb. p. 65 
la escritura frente al habla durante la época que Derrida denuncia como logofonocéntrica, porque es esta escritura vigilada por la dialéctica, por la lupa policial de la metafísica, una escritura que una vez nos brinda la verdad o nos traduce el pensamiento resulta desechable, lo que asume el concepto de escritura tradicional, habitual, lo que asume una escritura que se confunde con la inscripción, con la grafía, adaptada a un rol de suplemento mnemónico o de simple archivo que no le corresponde.

Contra este tipo de lectura, se podría invocar o provocar aquí la siguiente hipótesis: el artista es el "entre", la differencia, esa nada productiva que pone a obrar el texto o que pone a pensar la escritura. No se trata de un trabajo de mediación, no se trata de entender al artista como medium que trae esa verdad de la Verdad, o como el chamán que desvela la verdad del arte para plasmarla en la obra. Si la differencia no es algo, esto o lo otro, si no se trata de caer en la trampa de la vieja rejilla de la metafísica y reenviar, una vez más, todo fundamento o esencia a un mundo incorruptible, a un mundo al margen del mundo, ese tercero que a fin de cuentas se convierte siempre en lo primero y que actúa entre la obra y el artista no es una objetividad ideal, sino un poner a obrar que no cae por completo ni del lado del idealismo ni del lado del materialismo, ni se identifica absolutamente con la práctica o con la teoría, que, a fin de cuentas, asumiría la complejidad de las cosas. El artista al crear la obra, el escritor al escribir el texto, el filósofo al poner a pensar la escritura, son manejados y conducidos por ese poner a obrar en la misma medida en el que manejan y conducen ese obrar. Como defiendo en relación a ese doble gesto al que llamo archilectura -que toda lectura implica ya una escritura, que no hay lectores sino lectoescritores-, también "poner a obrar" en el sentido de escribir, crear, implica un doble movimiento en el que se conduce el trazo desde dentro y a un mismo tiempo ese trazo es conducido desde fuera. $Y$ de nuevo una prevención: no hay que entender aquí ese afuera en el sentido de las musas o el espíritu, o en el sentido de algo esencial con el que el artista se conecta, sino que ese afuera, además de referirse a la herencia, al corpus precedente, a ciertas reglas implícitas y explícitas que tienen que ver con la tradición, pone en evidencia, también, la complejidad del yo, la falsedad del cogito entendido como interioridad absoluta. Ese afuera pone en evidencia la grieta por la que el yo es siempre ya algo externo.

Cualquier asunción de la dualidad bruta se mueve en contra del "poner a obrar" al que aquí me refiero. No hay obra ni texto si todo es cálculo, si planifico una verdad que pretendo desvelar o si me aseguro de antemano un pensamiento que pretendo traducir. No hay artista, no hay escritor, no hay filósofo sin riesgo. Podemos, luego, marcar las diferenciaciones que sean necesarias -si caso surge esta necesidad- para distinguir a uno 
de otro, pero eso previo es común: no hay artista, escritor o filósofo que no ponga a obrar el texto, que no ponga a pensar la escritura.

Si la obra, en tanto que obra, no copia el mundo, sino que abre mundo ${ }^{20}$, poner a obrar la obra es abrir un espacio habitable en medio del "entre", es transformar el vacío de la nada en nada productiva, es edificar en la differencia una morada, es, a fin de cuentas, transformar la vida en sobre-vida, en vivencia por encima del mero vivir.

La inutilidad del arte, de la literatura, de la filosofía consistiría en crear espacios de resistencia a la mera vida, a esa vida que se limita a la supervivencia, al mero pasar o dejarse pasar por ella. No se trataría de otorgarle un sentido a la vida, sino de poner a obrar el instante; no se trataría de dar con un sentido global entendido en clave teleológica, sino de una narración siempre en marcha, cuyo sentido se abre y se cierra al hilo de su trama, cuyo sentido no admite clausura. El compromiso no es con la verdad de la Verdad, con cierta verdad absoluta y final, sino con el desvelamiento del instante presente que, a fin de cuentas, consiste siempre en un presente que no se presenta, que en sí mismo es ya una complejidad temporal, una complicación en origen.

Podemos hablar de lucha, de acontecimiento, de desvelamiento, pero no de verdad, no afirmar que la obra revela la verdad o que el compromiso del filósofo, del escritor, del artista, sea buscar la verdad, porque hablar de verdad es nombra algo preconcebido.

¿Qué es la verdad? Preguntar así por la verdad implica una negligencia en el uso, dice Heidegger, ya que nos estamos refiriendo a algo auténtico, real21. El compromiso con la verdad es el compromiso con algo ideal, que nunca se alcanza. Aquí, el filósofo es efectivamente el amigo de la filosofía, entendiendo este amigo como se entiende en las cantigas galaico-portuguesas, como el amante en la distancia, como aquel que ama lo que sabe que no alcanzará jamás. Por el contrario, lo que propongo aquí es el compromiso

20 "Lo mismo le ocurre a la estatua que el vencedor de la lucha le consagra al dios. No se trata de ninguna reproducción fiel que permita saber mejor cuál es el aspecto externo del dios, pero sí se trata de una obra que le permite al propio dios hacerse presente y que por lo tanto es el dios mismo. Lo mismo se puede decir de la obra literaria. En la tragedia no se muestra no se representa nada, sino que en ella se lucha la batalla de los nuevos contra los antiguos dioses (...) ya no habla sobre dicha batalla, sino que transforma el relato (...) de tal manera que, desde ese momento, cada palabra esencial lucha por sí misma la batalla y decide qué es sagrado o profano, grande o pequeño". lb. p. 73. De igual manera, la archilectura como poner a pensar la escritura o el arte como poner a obrar el texto, tampoco proponen una escritura que diga la verdad, sino que esta se juegue y se luche en cada palabra, en cada giro.

21 "La negligencia con que usamos esta palabra fundamental nos indica lo pequeño e imperfecto que es nuestro conocimiento sobre la esencia de la verdad. Cuando decimos verdad solemos referirnos a esta y aquella verdad, es decir, a algo verdadero". Ib. p. 85. 
con la escritura, con el instante concreto, con poner a obrar el texto o poner a pensar la escritura, con un doble movimiento que no se identifica de forma bruta con uno de los pares enfrentados por la vieja rejilla, sabiendo que se trata de un movimiento y de un compromiso sin clausura, sin más meta final, sin soluciones absolutas. Pongo el ojo, el sentido del ojo no en el archê o en el telos, sino en la narración.

El problema de la verdad, para Heidegger, es entenderla como concordancia con la cosa, para lo cual, la cosa debería mostrarse tal y como es. En este texto que planteo aquí, el problema de la verdad es entenderla como copia de un original o reproducción de un modelo, como traducción de un pensamiento que expresaría esa verdad más allá de su cuerpo de letra, como si el lenguaje consistiese en buscar un ropaje con el que cubrir esa verdad desnuda que habitaría un mundo al margen del mundo.

Cuando Heidegger entiende la verdad de otra manera, no como adecuación o concordancia o corrección sino como desvelamiento, hay que entender que este desvelamiento no es un hecho sino un acontecimiento ${ }^{22}$. No es algo, por tanto, que quede disponible, ahí a mano, para las ciencias de hechos, no es algo listo para la medida y el cálculo. El acontecimiento apenas se deja ver, apenas se deja decir, abre un "claro", un "entre", una differencia en la cotidianidad, en el día a día, en el espacio habitual, próximo, predecible. Poner a obrar el texto, poner a pensar la escritura busca, entonces, la irrupción del acontecimiento. "En la obra la que obra es la verdad, es decir, no solo algo verdadero"23. No deberíamos confundir lo verdadero, esto y aquello, con la verdad; no deberíamos confundir los entes de la verdad con su ser. Cuando afirmo que el compromiso del filósofo no es con la verdad sino con la escritura, en concreto con poner a pensar la escritura, cuando afirmo que la obra de arte no muestra una verdad sino que de lo que se trata es de poner a obrar la verdad, niego, por tanto, cualquier aproximación a la verdad de la Verdad, a la esencia de la verdad con mayúsculas, a que el texto o la obra se vean obligados a entregar una verdad entendida como eterna y universal. En todo caso, se trata de abrir un espacio, que no será nunca un espacio vallado o domesticado del todo sino un espacio salvaje, donde se pueda poner en juego la verdad, donde puedan surgir verdades, donde el receptor está obligado no a una recepción pasiva sino a una recepción que pasa por la elaboración de su propio texto.

22 "El desocultamiento de lo ente no es nunca un estado simplemente dado, sino un acontecimiento. El desocultamiento (la verdad) no es ni una propiedad de las cosas en el sentido de lo ente ni una propiedad de las proposiciones". lb. p. 93.

23 lb. p. 97. 
El arte, la escritura; la obra, el texto, deben permitir la posibilidad del acontecimiento, no entregar una verdad sino permitir la posibilidad de que cierta verdad acontezca. Si el acontecimiento de la verdad forma parte de la esencia de la obra, ¿qué es la verdad para que se dé como acontecimiento?, ¿qué es la verdad para que no remita solo a cosas o a hechos verdaderos?

\section{4. ¿Qué obra en la obra?}

Cuando Heidegger afirma que "en la obra, obra el acontecimiento de la verdad" 24 , y que se presupone la obra como soporte de dicho acontecimiento, hay que andarse con cierta precaución ante esta idea de "soporte" que de alguna manera es similar a la utilizada durante la época del logofonocentrismo para entender el lenguaje como soporte del pensamiento y la escritura como soporte del habla, como medio más o menos prescindible que, simplemente, traslada el sentido, la verdad. Este acontecimiento de la verdad, o esta verdad que acontece, no utiliza la obra como mero soporte para materializarse, no respira ni vive si no es en la obra misma. Dicho de otra forma, la obra no trae, o expresa, o es el continente de un contenido que la precede. El acontecer, acontece en el mismo poner a obrar la obra.

Me gustaría matizar también la condición de la obra como algo efectuado. Tampoco entendería aquí un cierre, un objeto creado ya y para siempre del que extraer cierta verdad única, inamovible. La obra, el texto, no tienen clausura, no son algo "ya" efectuado sino algo que siempre se está efectuando, abierto siempre a la posibilidad del acontecimiento de la verdad o de que cierta verdad acontezca.

Que en la obra, obre el acontecimiento de la verdad, no significa que la obra sea el acontecimiento de la verdad, o que la obra entregue la verdad ${ }^{25}$, ni mucho menos que en la obra o que en el texto haya que leer cierta verdad que se muestra ahí pero que sería previa a ese mostrase, sino que la obra, más que ofrecer un producto final, sigue obrando mientras sea obra, mientras se mantenga como abertura para que una verdad acontezca ${ }^{26}$. Lo que la obra pone delante no es la verdad, sino cierta "grieta", cierto "entre", cierto

24 lb. p. 99.

$25 \mathrm{Al}$ igual que no identificamos la differencia con algo, con esto o con lo otro, la verdad como acontecimiento no es la obra, la verdad -lo he dejado escrito antes- no es.

26 Que la obra se mantenga en obra, como veremos, no depende solo del artista sino también -quizá sobre todo- de aquellos a los que Heidegger denomina como cuidadores y en mi propuesta llamo archilectura. 
"espacio" sin localización al que podemos denominar así: posibilidad de acontecimiento ${ }^{27}$. Dicho de otra forma: la obra no plasma la verdad, no es una imagen, una reproducción o una instantánea de la verdad, de una verdad que estaría fuera de ella.

Toca preguntarse, con Heidegger, qué es entonces la verdad para que esta tenga que acontecer así (por más que esa estructura que formula "qué es" la usemos con las mayores de las precauciones):

La verdad es no-verdad, en la medida en que le pertenece el ámbito de procedencia de lo aún-no (de lo no-) desocultado en el sentido del encubrimiento. (...) La verdad es la lucha primigenia en la que se disputa, en cada caso de una manera, ese espacio abierto hacia el que adentra y desde el que se retira todo lo que se muestra y retrae en tanto que ente ${ }^{28}$.

Al igual que respondía a la pregunta "qué es el arte", responderé a la pregunta "qué es la verdad" con un "no es". Una respuesta que no contesta a la pregunta inmediata sino a la aceptación acrítica e implícita que acepta que eso por lo que se pregunta, es. Así, responder a "qué es" con un "no es", revisa la estructura de la misma pregunta, viene a decir: al preguntar "qué es", se afirma una cualidad de eso por lo que se pregunta, se admite, por tanto, cierta precomprensión, cierto saber "qué es" eso que interroga el "qué". Responder "no es", invita a colocarse en un paso anterior al contrato, a la aceptación de la evidencia. Por tanto, a ¿qué es la verdad?, respondo: no es.

Si la verdad se produce como desvelamiento, si no se manifiesta como hecho sino que acontece o se ofrece como acontecimiento, como ese acontecimiento que no se deja nunca apresar o decir del todo, que no es nunca un objeto de cálculo para las ciencias exactas, que no es nunca un ente del todo cuantificable, del todo definible, del todo mensurable, la verdad, entonces, "no es"; o al menos, no es esto o lo otro, no responde al mito de la presencia. No la verdad de la Verdad, ni la verdad en abstracto o una verdad universal, sino la verdad como ese campo de batalla que aquí defino como poner a obrar la obra o la letra, como poner a pensar la escritura. Desde esta posición no resulta válida, por tanto, ninguna representación, ningún reflejo, ninguna copia, ninguna traducción, ninguna representación de un objeto "real", ningún reflejo de un cuerpo "existente",

27 Lo que denomino "grieta" es también la posibilidad del yo no entendido como cogito si por ello se invita a acierto solipsismo o a la división tajante entre la interioridad del yo y el exterior de un afuera. La "grieta" crea siempre una exterioridad en el interior, una exterioridad interna, que es lo propio del yo, que provoca que el yo sea ya otro, que advierte que no hay yo absoluto o puro frente a un completamente otro, sino que lo que se da es un complejo yo-otro/otro-yo al que vengo denominando yotro y que impide caer en las simplicidades de la vieja rejilla.

28 EOA. p. 105. 
ninguna copia del "original", ninguna traducción de un pensamiento que precedería al lenguaje. La representación es ya presentación, la copia es ya el original, la traducción es ya el texto fuente. Invirtiéndolo: toda presentación es ya "re-presentación", todo original es ya una copia, todo texto fuente aparece ya traducido. La verdad, por tanto, como "entre", differencia, grieta, espacio salvaje, sin cierre ni clausura.

Si retomo lo afirmado más arriba, que podemos considerar así también al artista, volvemos a esa circularidad entre la obra y el artista, entre el huevo y la gallina, como si se afirmase, entonces, que el artista es la verdad, o que la verdad es el artista. Se puede admitir cierta conexión (voluntaria o involuntaria) entre la verdad y el artista; pero no en el sentido de la verdad como adecuación o como hecho, no en el sentido en el que el artista nos pone ante la verdad de la Verdad gracias a la obra que él crea, sino que el compromiso del artista, del escritor, del filósofo, es con ese poner a obrar como posibilidad para que la verdad acontezca; sin garantía de que ocurra, sin red de seguridad, sin contrato por el que se le promete una contrapartida a su labor. No hay aquí un saber profesional que asegure resultados; no hay aquí la maniobra del especialista que, prometiendo encontrar lo propio del asunto, se autonomina de forma tácita y algo perversa propietario de todo aquello que cae dentro del trozo de terreno que ha vallado como "su" especialidad.

Por supuesto, no se trataría tampoco de ciencia si por esto entendemos la construcción de un ámbito de verdad y no un acontecimiento originario de la misma, un acontecimiento que correspondería (siguiendo la lectura de Derrida) con un origen no simple, sino con una complicación originaria.

La ciencia no es ningún tipo de acontecimiento originario de la verdad, sino que es siempre la construcción de un ámbito de verdad (ya abierto) que se logra al aprehender y fundamentar todo lo que, dentro de su círculo, se muestra como cierto y correcto tanto bajo el modo de lo posible como bajo el modo de lo necesario. Cuando y en la medida en que una ciencia va más allá de lo correcto para alcanzar una verdad (esto es, un desvelamiento esencial de lo ente en cuanto tal) dicha ciencia es filosofía ${ }^{29}$.

Construcción de un círculo, de un ámbito, de un modo necesario de corrección de lo posible y de lo necesario, delimitar la tierra del especialista, los trozos de un mundo mensurable, las cosas que se ajustan a las posibilidades de su cálculo. No hay especialista, ni saber de cosas, ni ciencia de hechos, sin agrimensura previa, sin un acotar el tablero de juego y definir las reglas o la axiomática fundamental que ha de dirigir la mirada. "Su" mirada, que para el especialista, es todo cuanto hay; lo único necesario, lo único posible.

29 lb. pp. 107 y 109. 
Querría matizar, también, que cuando Heidegger dice, o se traduce lo que ha escrito como que "la verdad se establece en la obra" ${ }^{30}$, no me parece lícito tampoco aquí entender "establecimiento" como posición ganada o como verdad establecida ya para siempre, como una verdad que haya que recibir de forma pasiva, que haya que explicar o comprender sin más, que haya solo que leer o ver. La verdad no es un hecho, sino un espacio de trabajo, la verdad está siempre por venir, es siempre, por tanto, impredecible; no se puede "pre-ver" o "pre-anunciar", no se deja "pre-comprender". La verdad no tiene futuro; tiene, en todo un caso, un por venir, un por llegar.

El "entre", la differencia, como la lucha que Heidegger define como intimidad mutua de los que luchan, de aquello que está en lucha, y que remite, también, a la vida secreta, a una sobre-vida o super-vivencia que poco tiene que ver con la del especialista o con la del profesional público. No hay nada que hacer si no se entra en la lucha, si la lectura o la visión no se deja alcanzar por cierta intimidad de la obra, del texto, si no hay un pacto con el secreto, con un secreto que no se deja exponer nunca del todo, que no se deja convertir por completo en objeto cultural o de conocimiento y que, por supuesto, no remite en exclusiva a la utilidad.

Más que especialistas, profesionales, académicos, lo que se precisa es lo que Heidegger llama "cuidadores" y yo llamo aquí archilectores. Se precisa poner en práctica una recepción que no está exenta de acción, un heredar que no se limite a la dilapidación de la herencia, una lectura que sea, a su vez, escritura. Ese cuidar al que se refiere Heidegger no tiene que ver con la observación neutra u objetiva de la ciencia, no tiene que ver con ese saber de autopsia, con el conocimiento forense que trata a sus cuerpos como objetos inorgánicos, sino que

cuidar la obra significa persistir en mantenerse siempre en el interior de la apertura de lo ente acaecida en la obra. (...) esta interna persistencia del cuidado es un saber (...) Saber no consiste solo en un mero conocer o representarse algo $^{31}$.

No se trata de "aplicar" un saber, una metodología o un protocolo decidido de forma previa, sino que se trata, como se ha repetido, de poner a obrar la letra o la obra, de poner a pensar la escritura, de respetar ese espacio abierto donde reside la posibilidad (nunca la certeza) de cierta verdad como acontecimiento, como eso que, a fin de cuentas, no se dejará en ningún caso cerrar del todo, decir de una vez y para siempre.

30 lb. p. 109.

31 lb. p. 117. 
Heidegger propone una muy interesante imbricación entre querer y saber; hay que querer saber, pero hay, también, que saber querer. Como he defendido en alguna otra parte, no sabemos nada demasiado y sabemos demasiada nada ${ }^{32}$. Por supuesto, saber qué quiero, saber qué quiero saber, remitiría ya a una precomprensión y a una delimitación previa de eso que pretendo saber. La complicación, en todo esto que se está proponiendo es, quizá, no seguir operando con las maneras de la vieja rejilla, no seguir entendiendo los contrarios como dualidades duras, no porosas. Al igual que defiendo que leer es ya escribir, al igual que la deconstrucción no propone una etapa en la que se destruye y a la que le seguiría otra en la que se construye, sino que evita este tipo de causalidad o de cronología procesual, proponiendo un construir y un destruir que se dan al mismo tiempo, en un mismo tiempo que siempre difiere, en un presente dislocado que no se presenta, tampoco en este caso puedo saber lo que quiero, sino que ambos movimientos, el querer, el saber, se cruzan, se solapan, se reúnen y se separan el uno del otro. Se trata, como siempre, de la asunción de la complejidad.

En relación a lo dicho, por tanto, el saber vendría a ser un querer mantenerse en la lucha, en la intimidad del poner a obrar -en este sentido identificaba al artista con el "entre" o la differencia-. Esta lucha no es abstracta, no responde a una idea universal e ilocalizable, sino que se materializa o se fija en la obra, sin que este fijar implique cierre o clausura del sentido u obligue a cierta verdad que se debe acatar. Esta lucha, este espacio entre la obra y la artista, es el tercero que termina siendo siempre lo primero. No se trata de la esencia del arte como pureza al margen del mundo con la que el artista se debe conectar y cuya obra, como resultado, representaría; al igual que no se trata del genio del artista que genera obras de arte en cada acción, a cada trazo. Si no hay obra sin artista ni artista sin obra, hay que entender que ambas partes se reúnen y se dislocan en ese espacio de lucha, en el campo de batalla donde, al menos, se abre una posibilidad para que la verdad acontezca.

A pesar de cierta circularidad ya comentada, hacia el final de su texto Heidegger parece apostar por la preeminencia de la obra. "Es la obra la que, por su esencia, hace posible a los creadores y necesita a los cuidadores"33. Aun así, la pregunta por el origen, por el origen del arte, por el arte como origen, sigue abierta. Aquí, habría que entender origen en la dirección en la que estamos proponiendo la verdad, esto es, como acontecimiento, como algo, por tanto, que no tiene que ver con un punto temporal o cronológico fijado a la línea del tiempo; al contrario, se trataría de un origen que permanece en activo, que está

32 SEgoviA, C. El espacio salvaje: la bestia de Derrida en la isla de Robinson. Madrid, Ápeiron, 2017. Esta sería -si se pudiese hablar de tesis (que no se puede)-, la tesis principal de este trabajo.

33 EOA. p. 125. 


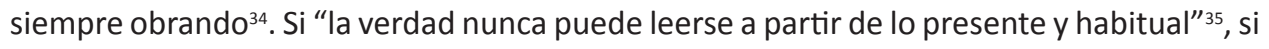
no es una cosa, un hecho, una interpretación donada, algo que esté ahí, listo para su uso, disponible para una ciencia de hechos, etc., tampoco el origen remite a un punto presente pasado concreto. El origen de la obra de arte no es tanto la verdad cuanto la posibilidad de que la verdad acontezca, más que un origen de la verdad, habría que referirse a una verdad que se origina, que obra, que está siempre en proceso de originarse.

Llevando a un terreno común la obra y el texto, tomo ahora lo que deja escrito Heidegger en relación a que "todo arte es en esencia poema". Y aquí, Heidegger vuelve a repetir que la esencia del arte es ponerse a la obra de la verdad; es decir, no poner la verdad en la obra, sino ponerse a la obra de la verdad, en proceso, en camino, abriendo en la obra la posibilidad de que la verdad acontezca. Y la obra, no lo olvidemos, es la pintura y es el texto.

No se trata, tampoco, de efectismos, del efecto que la obra puede causar, no se trata, por tanto, de cálculo.

La eficacia de la obra no consiste en el efecto que produce. Consiste en un cambio que tiene lugar a partir de la misma obra del desocultamiento de lo ente, o lo que es lo mismo, del ser ${ }^{36}$.

Quiero marcar esta cuestión del "cambio", porque eso es precisamente lo que obra todo acontecimiento, un cambio, que algo cambie, que algo habitual, común, natural, evidente, deje de serlo. El acontecimiento abre una grieta.

Por supuesto, sería un error demasiado grueso confundir aquí poema con "bella letra", con un género literario, con verso, con cierta disposición tipográfica del cuerpo de letra sobre la hoja o la pantalla, ni siquiera con cierta escritura. Es más, el poema no queda nunca inscrito; es escritura pero no grafía. El poema al que aquí me refiero es ese excedente del texto utilitario, académico, especializado, erudito, es el excedente lo que transforma lo escrito en escritura, el exceso de energía lo que pone a obrar, lo que pone a pensar la escritura.

34 Sería fácil entender que aquí me estoy refiriendo al archê al menos en uno de sus sentidos. No como origen o start, no como algo antes de lo cual nada, sino como principio diacrónico sino como principio diacrónico, como eso que hace que algo siga siendo. Por más cómoda que resulte esta analogía, hay que tener en cuenta que nos e trata de entender ese principio como alego previo que ha generado eso que es y que hace que siga siendo, ni tampoco como una esencia colocada fuera, externa.

35 EOA. p. 125.

36 Ib. p. 127. 
El propio Heidegger reconoce que afirmar eso, que todo arte es poema, resulta una suposición arbitraria "mientras sigamos opinando que las citadas artes son variantes del arte del lenguaje" ${ }^{\prime 37}$. Para Heidegger, poesía no remite a literatura -entendida esta de la peor de la formas-, sino que es uno de los nombres del poner a obrar, de posibilitar el acontecimiento. Ni siquiera hay que entender aquí el lenguaje como comunicación entre emisor y receptor, como representación de las cosas, como traducción del pensamiento. El poema es el relato del acontecimiento, eso que no se deja nunca decir del todo. Es la narración la que pone a obrar la verdad y la que abre sujeto. La verdad no es un hecho; es una narración, es un texto.

Heidegger insiste en la necesidad del cuidador; no del especialista, no del científico objetivo que observa desde fuera, no de patólogo o el diseccionador de cadáveres, sino del cuidador, ese o esa que aquí he propuesto como lectoescritor, como aquel o aquella que no se limita a leer para luego explicar, sino que pone en marca una archilectura, un leer/escribir complejo, una lectura, a fin de cuentas, que se hace cargo y se compromete con la escritura que pone en marcha, que no se lava las manos ante su propia letra. ¿No está practicando Derrida, en este texto que seguimos, una archilectura del texto de Heidegger? Porque no se irá a afirmar que Derrida explica o se lanza a una hermenéutica de ese texto que toma sin apropiárselo, no se irá a afirmar que Derrida se presenta como un especialista en Heidegger, o que no pone en marcha un texto que interesa por sí mismo, al margen de lo que "explique", "traduzca" o aclare acerca del texto del que toma punto de partida. No se irá a decir que Derrida no crea su propio Heidegger, porque la clave está en ese verbo: "crear", porque sin crear la obra, el texto, sin ponerlo a obrar, no hay conocimiento posible.

Este arte como poema -decía Heidegger ${ }^{38}$-, este poner a obrar es lo que se entiende como fundación o como origen. No un comienzo a modo de génesis absoluta antes de la cual nada. No hay un punto previo que no remita a una complejidad en origen.

El arte hace que surja o salte afuera la verdad. (...) Hacer surgir algo por medio de un salto hacia delante, llevar algo al ser a partir de ese lugar de

\section{$37 \mathrm{lb}$.}

38 Hagamos notar que no se trata del poema que defiende Gadamer para seguir priorizando la voz frente al texto, el habla frente a la escritura. No se trata, al menos no lo que yo defiendo aquí, de la voz recitando el origen, de entender la voz en relación con la verdad, etc. No hay voz sin escritura, no hay origen sin proceso narrativo. Que el origen sea un proceso impide entenderlo como puro punto absoluto. 
donde procede la esencia por medio del salto fundador, eso es precisamente lo que significa la palabra origen ${ }^{39}$.

Origen, por tanto, como un comienzo de nuevo, como un origen otra vez, como una nueva fundación. En este sentido "el arte es en su esencia un origen" ${ }^{40}$. ¿Cuál es, por tanto, el origen del arte? El arte mismo, su poner a obrar. Entender que se trata de la posibilidad del acontecimiento es su verdad.

Por tanto: ¿qué obra en la obra? Un nuevo comienzo. Ver, entender, leer "como si" fuese la primera vez. El texto que obra ofrece siempre una nueva lectura; no hay mecanismo hermenéutico que pueda con él, análisis que lo cierre, conferencia de notables que lo clausure. En este sentido, la filosofía como escritura, como arte, como si el arte fuese posible. En este sentido, la filosofía obra, y lo hace como arte, como si el arte fuese posible.

Al igual que Heidegger reconoce en el epílogo de su texto, no se trata de resolver el enigma sino de verlo, no se trata de decir qué es la verdad o qué es el arte o qué es el acontecimiento sino planear sobre ellos, aproximarse, extraviarse, volver. Como se habrá entendido, cualquier ambición definitiva se ha dejado aquí de lado en origen. Fijar la verdad, una verdad, no se opone a dejar acontecer, más bien lo contrario, la verdad solo fija cierta verdad en el ponerse a obra de la obra. Y este dejar, tal como Heidegger escribe en el apéndice a su texto, no tiene nada que ver con la pasividad, sino que es, para él, "el quehacer supremo"41. Retomamos aquí la cuestión del querer y del saber, del querer saber, pero también del saber querer, que pasa por la administración de esa posibilidad de la verdad como acontecimiento y no como dato o hecho bruto.

¿A quién pertenecen las botas?, ¿ese par o simplemente esas dos botas que hemos dejado atrás? Pues ni a una campesina ni a un citadino, ni a Van Gogh ni, por supuesto, a Schapiro. Esas botas pertenecen al camino, ese camino que en su caso, en el caso de una botas pintadas, no tiene recorrido. $Y$ a pesar de eso, lo que nos han hecho caminar esas botas, la de sendas que provocan, la de bifurcaciones que fuerzan, la de kilómetros que llevan ya bajo sus suelas. A pesar de su inutilidad, lo que nos han hecho movernos esas botas que no son unas botas.

¿Qué obra en la obra? Movimiento, un moverse sin paso, podríamos contestar. O un moverse al paso del poner a obrar. Pasos que no nos llevarán a ninguna parte si por llegar entendemos meta final, resolución del camino, telos o sentido último y absoluto.

39 EOA. p. 137.

$40 \mathrm{lb}$.

41 lb. p. 147. 
A fin de cuentas, responder al "qué es", responder a qué es el arte, a qué es la verdad, son solo una serie de orientaciones para afinar la pregunta, para volver, otra vez, a preguntar ${ }^{42}$. La verdad implica el "poner y ponerse", tanto el de la obra como el del sujeto. Este "poner-se" es el tercero que resulta siempre primero. Se trata de poner a obrar la obra, pero también de "poner-se" a obrar, al igual que poner a pensar la escritura implica una archilectura, una lectoescritura, un leer que de forma instantánea provoca ya "otro" texto. Poner a obrar la verdad como ponerse a la obra de la verdad, es decir: abrir la posibilidad para el acontecimiento.

\section{Conclusión sin clausura: la verdad fetichista}

Para terminar, que no cerrar, cito un fragmento del primero de los estudios que componen La verdad en pintura:

Kant propone otra metáfora (...) el filósofo puro, el metafísico, deberá obrar como un buen arquitecto, como un buen technites de la edificación. Será una especie de artista. Ahora bien, ¿en qué caso un arquitecto es, según Kant, bueno? (...) En primer lugar debe garantizar el fondo, los cimientos o el fundamento ${ }^{43}$.

Claro que Kant se refiere al filósofo puro, al metafísico, a esa figura que se niega desde hace unos cuantos años, más de un siglo, a esa figura espectral que aun enterrada se levanta y anda, quizá con esas botas de la pintura de Van Gogh que no se han creado para caminar pero que este fantasma insiste en calzarse. Claro que del filósofo como artista, del filósofo que pone a obrar el texto, que pone a pensar la escritura, no esperamos esa garantía de base, que asegure unos cimientos inamovibles, que nos proporcione un fundamento cierto, verdadero, universal, imperecedero. Pero lo que sí le pedimos es que se comprometa con el texto que edifica, que sea una "especie" de artista, entendido -o quizá no entendido en absoluto- en la dirección que hemos venido exponiendo.

La verdad de la Verdad, la verdad como adecuación, entender que la obra de arte representa una realidad fuera de ella misma, que copia o imita, igual que entender que el habla dice el yo, que el lenguaje traduce el pensamiento y que la escritura se limita a registrar ese trasvase, todo esto tiene que ver, más que con la verdad metafísica, con la verdad fetichista -si acaso estas dos verdades no remiten solo a un tipo de verdad.

42 "Lo que parece una respuesta es una mera serie de orientaciones para la pregunta". Ib. p. 151. 43 LVP. p. 52. 
Y claro que con zapatos de por medio, con objetos fuera de uso, extraviados, tiene que aparecer por fuerza la cuestión del fetichismo. Estas cosas del fetichismo aparecerían, al menos, desde la vertiente marxista y desde la vertiente psicoanalítica.

Como explica Anselm Jappe, Marx nombra a los seres humanos como guardines de la mercancía, ya que estas no pueden concurrir solas al mercado, ya que estas no se vendan a sí mismas ${ }^{44}$. Comparemos los "cuidadores" de Heidegger con los "guardianes" de Marx, ¿acaso no hay, de una y otra parte, el riesgo de caer en la autoapropiación y el fetichismo?, ¿acaso no se ha corrido el riesgo, y se ha caído del todo en ese riesgo, de que los cuidadores se conviertan en especialistas y los guardianes en propietarios?

No es posible entrar ahora por esta puerta que se abre o que al menos se entorna e invita a futuros textos por venir. Remarcar solo lo siguiente, cuando Jappe afirma que "el capitalismo no es el dominio de una clase sobre otra, sino el hecho de que la sociedad entera esté dominada por abstracciones reales y anónimas" 45 , cuando se recuerda que Marx habla de "sujeto automático", hay que comenzar, quizá, a unir ciertos puntos de fuga en todo esto que venimos leyendo aquí, porque la cuestión de la representación, de la traducción, de la verdad como adecuación, de la idealidad pura al margen del mundo, nos lleva a lo que suelo referirme como fábrica de absoluto. Esta cuestión del fetichismo desde la óptica marxiana o marxista -si acaso es posible seguir utilizando este tipo de etiquetasabriría, por tanto, un campo para la cuestión de la representación y de la proyección que aquí solo es posible anunciar.

Desde el lado psicoanalítico. ¿Acaso la maniobra del especialista, esa obsesión de Schapiro por proponerse de forma tácita y encubierta como propietario de los zapatos de Van Gogh a los que busca su legítimo propietario, no es similar a lo que ocurre, por poner un ejemplo, en el comienzo de Él, la película de Buñuel ${ }^{46}$ ? Este filme, de su época mexicana, arranca en el interior de una iglesia. Mientras tiene lugar el oficio, la pantalla muestra, gracias a un plano detalle, unos zapatos de mujer. $Y$ enseguida el rostro de un hombre que fija sobre ellos la mirada, una mirada que luego busca la dueña de esos zapatos, una mirada que sube por la piernas de la mujer hasta llegar a su cabeza, que busca la propietaria de esos zapatos que en el fondo ese hombre quiere para sí. Al igual que ocurre con Schapiro cuando le discute a Heidegger si se trata de los zapatos de un hombre o de una mujer, al igual que discute si son para el campo o la ciudad, pero en el

44 "De lo que es el fetichismo de la mercancía y sobre si podemos librarnos de él", JAPPE, A. prólogo a MARX, K. El fetichismo de la mercancia (y su secreto). Logroño, Pepitas de calabaza, 2014.

45 Ib. p. 13

46 Buñuel, L. Él. México. Ultramar Films. 1953. 
fondo, su maniobra es apropiárselos, conseguir que esos zapatos sean finalmente suyos, el hombre que observa los zapatos en el arranque del filme de Buñuel, por más que luego busque con la mirada que asciende por el cuerpo de la mujer a la propietaria de esos zapatos, ese hombre, lo que quiere -sus ojos lo dicen, sus ojos hablan al igual que los zapatos de Van Gogh nos hacen caminar- es apropiarse no de la mujer sino de los zapatos. ¿Y no es esto lo que tantos hombres desean sin saberlo?, ¿no la mujer sino sus zapatos? 0 dicho de otra forma: ¿no la persona sino cierta parte, cierta función, cierta representación de ella? Bien, esto daría para un camino demasiado largo ya. Para los caminos que se abren a partir de aquí, las suelas de esos zapatos de Van Gogh, por más que sean unos zapatos pintados, están ya demasiado gastadas.

\section{Bibliografía}

Buñuel, L. Él. México. Ultramar Films. 1953.

DERRIDA, J. La verdad en pintura. Traducción al español de M. C. González y D. Scavino. Buenos Aires, Paidós, 2009.

HEIDEGGER, M. El origen de la obra de arte. Traducción al español de H. Cortés y A. Leyte. Oficina de Arte y Ediciones, 2016.

JAPPE, A. "Prólogo" a MARX, K. El fetichismo de la mercancia (y su secreto). Traducción de D. L. Sanromán. Logroño, Pepitas de calabaza, 2014.

SEGOVIA, C: "El sujeto narrado: poner a pensar la escritura". Revista Electrónica de Investigación en Filosofía y Antropología. Decanato de Filosofía. UNED, 2017.

SEGOVIA, C. El espacio salvaje: la bestia de Derrida en la isla de Robinson. Madrid, Ápeiron, 2017

SIEGEL, D. La invasión de los ladrones de cuerpos. EEUU, Allied Artists, 1956. 